\section{JURNAL EKONOMI EFEKTIF}

ISSN : $2622-8882$, E-ISSN : 2622-9935

Jurnal Ekonomi Efektif, Vol. 4, No. 1, Oktober 2021 @ Prodi Manajemen Fakultas Ekonomi Universitas Pamulang

\title{
PENGARUH BUDAYA KERJA TERHADAP PRODUKTIVITAS KARYAWAN PADA PDAM (PERUSAHAAN DAERAH AIR MINUM) DI JAKARTA
}

\author{
Berliana $^{1 *}$, Indri Lastriyani², Muhammad Firman ${ }^{3}$ \\ STKIP PGRI Sukabumi, Sukabumi, Jawa Barat, Indonesia \\ berliana@stkippgrisukabumi.ac.id ${ }^{1 *}$, indrilastriyani@ stkippgrisukabumi.ac.id ${ }^{2}$, \\ muhammadfirman@ @tkippgrisukabumi.ac.id ${ }^{3}$
}

Manuskrip: Agustus -2021; Ditinjau: September: -2021; Diterima: September-2021; Online: Oktober-2021; Diterbitkan: Oktober-2021

\begin{abstract}
ABSTRAK
Penelitian ini bertujuan untuk mengetahui pengaruh budaya kerja terhadap produktivitas karyawan pada PDAM (Perusahaan daerah Air Minum) di Jakarta. Metode yang digunakan adalah explanatory research dengan sampel sebanyak 93 responden. Teknik analisis menggunakan analisis statistik dengan pengujian regresi, korelasi, determinasi dan uji hipotesis. Hasil penelitian ini variabel budaya kerja diperoleh nilai rata-rata skor sebesar 3,427 dengan kriteria baik. Variabel produktivitas karyawan diperoleh nilai rata-rata skor sebesar 3,855 dengan kriteria baik. Budaya kerja berpengaruh positif dan signifikan terhadap produktivitas karyawan dengan nilai persamaan regresi $\mathrm{Y}=9,174+0,857 \mathrm{X}$, dan nilai koefisien korelasi 0,775 atau memiliki tingkat hubungan yang kuat dengan nilai determinasi $60,1 \%$. Uji hipotesis diperoleh signifikansi $0,000<0,05$.
\end{abstract}

Kata Kunci: Budaya Kerja, Produktivitas Karyawan

\section{ABSTRACT}

This study aims to determine the effect of work culture on employee productivity at PDAM (Regional Drinking Water Company) in Jakarta. The method used is explanatory research with a sample of 93 respondents. The analysis technique uses statistical analysis with regression testing, correlation, determination and hypothesis testing. The results of this study, the work culture variable obtained an average score of 3,427 with good criteria. Employee productivity variables obtained an average score of 3.855 with good criteria. Work culture has a positive and significant effect on employee productivity with a regression equation value of $Y=9.174+0.857 X$, and a correlation coefficient value of 0.775 or has a strong level of relationship with a determination value of $60.1 \%$. Hypothesis testing obtained a significance of $0.000<0.05$.

Keywords: Work Culture, Employee Productivity 


\section{PENDAHULUAN}

\section{A. Latar Belakang Masalah}

Budaya organisasi sebagai sebuah sistem makna bersama yang dianut oleh para anggota organisasi untuk yang membedakan organisasi tersebut dengan organisasi lainya (Robbins dan Judge, 2007:301). Budaya pada dasarnya memiliki keunikannya tersendiri, baik antar negara, pulau, provinsi, kota, kabupaten, desa, dan pedalaman sekalipun memiliki keragaman akan budayanya masing-masing. Budaya perusahaan adalah semua sistem nilai-nilai yang dirasakan maknanya oleh seluruh orang dalam perusahaan. Selain dipahami meyakini sistem nilai-nilai tersebut sebagai landasan gerak perusahaan (Robbins, 2003:122). Hal ini disebabkan karena, adanya suatu bentuk akan kecintaan terhadap kebiasaan, tradisi, seni, dan atau hal lainnya yang terdapat pada setiap tempat yang berbudaya.

Budaya organisasi merupakan sistem nilai, keyakinan, norma yang meresap yang ada di organisasi, budaya organisasi dapat mendorong atau melemahkan keefektifan, organisasi tergantung dasar nilai, keyakinan dan norma. (John, Robert, dan Michael, 2006:313).

Dalam bisnis terdapat faktor-faktor yang dapat mempengaruhi manajemen SDM Global, yakni politik, ekonomi, budaya, dan hukum. Didalam faktor-faktor yang mempengaruhi majamen SDM Global salah satunya adalah budaya. Budaya suatu organisasi yang mensosialisasi orang (Robbins, 2003 :312). Jadi, budaya adalah suatu faktor yang dapat mempengaruhi manajemen SDM, yang dapat menjadi masalah apabila keadaannya terhalang pada suatu hal tertentu. Untuk itu manajemen SDM harus memperhatikan faktor terkait khususnya budaya, karena apabila kebiasaan terus dibiarkan akan merusak budaya yang ada pada suatu perusahaan khususnyua pada manajemen perusahaan atau organisasi.

Suatu budaya yang kuat akan mendesak lebih banyak pengaruh serta mendukung atau mempengaruhui produktivitas dan kepuasan karyawan dengan dampak yang lebih besar pada budaya yang lebih kuat (Robbins, 2003: 308). Perusahaan atau organisasi membuat standar kerja guna untuk menciptakan anggota atau karyawan yang memiliki produktivitas kerja yang tinggi terhadap perusahaan atau organisasi. Banyak anggota atau karyawan yang kurang memperhatikan standar kerja yang telah ditetapkan oleh perusahaan atau organisasi, sehingga terciptanya budaya kerja yang dapat membuat produktivitas kerja anggota atau karyawan menurun. Selain itu, budaya kerja yang diterapkan oleh anggota atau karyawan dapat menjadikan suatu kebiasaan yang sulit untuk mengubahnya, sehingga memerlukan waktu untuk mengubahnya kembali.

Anggota atau karyawan tidak hanya membuat standar kerja tersebut menjadi suatu budaya yang akan menurunkan produktivitas kerjanya, tetapi dapat menaikkan tingkat produktivitas kerja yang tinggi sehingga dengan segera menjadikan tujuan perusahaan atau organisasi segera terealisasikan dengan cepat. Untuk itu banyak anggota atau karyawan yang menciptakan sendiri budaya kerjanya, karena setiap individu memiliki karakternya masing-masing dan juga mempunyai tingkat kecerdasan yang berbeda-beda. Seseorang dapat menciptakan budaya nya sendiri sesuai dengan tingkat kecerdasannya, yang dapat membuat suatu produktivitas kerja yang tinggi serta berdampak baik bagi perusahaan atau organisasi.

Produktifitas adalah kemampuan seperangkat sumber-sumber ekonomi untuk menghasilkan sesuatu sebagai perbandingan antara pengorbanan (input) dengan menghasilkan (output), (Sinungan, 2003: 12). Produktivitas kerja karyawan dihasilkan berdasarkan apa yang dikerjakan oleh karyawan itu sesuai dengan tanggung jawabnya didalam mengerjakan suatu tugas yang telah ditetapkan oleh perusahaan untuk 
menghasilkan hasil yang baik atau sesuai dengan target yang telah ditentukan oleh perusahaan. Mulyono (2004:3) mengemukakan bahwa "Produktifitas adalah hasil yang didapat dari setiap proses produksi dengan menggunakan satu atau lebih faktor produksi”.

Sebagai salah satu perusahaan terkemuka di Indonesia, perusahaan daerah air minum atau yang biasa disebut PDAM memiliki tugas pokok seperti: Melaksanakan pelayanan umum/jasa kepada masyarakat konsumen dalam menyedikan air minum, menyelenggarakan kemanfaatan umum yang dapat dirasakan oleh masyarakat, meningkatkan pendapatan untuk membiayai kelangsungan hidup perusahaan dan pembangunan daerah.

Sebagai perusahaan yang sudah lama berdiri budaya kerja yang diterapkan oleh PDAM seperti: Datang tepat waktu, ikut apel, pulang tepat waktu, bekerja terprogram, bekerja dengan tanggung jawab, pekerjaan yang terorganisir.

Budaya kerja yang baik adalah kebiasaan atau tradisi karyawan di dalam melakukan pekerjaan yang tidak dapat dihilangkan tetapi dapat menghasilkan produktivitas yang baik. Misalnya apel pagi sering telat, tetapi di dalam membuat laporan akhir selalu tepat dan cepat, atau sering tidur di dalam kantor setelah pekerjaan selesai padahal belum jam istirahat.

Berdasarkan latar belakang di atas, maka penuis tertarik melakukan penelitian lebih lanjut dengan judul "Pengaruh Budaya Kerja Terhadap Produktivitas Karyawan di Jakarta".

\section{B. Rumusan Masalah}

1. Bagaimana budaya kerja pada PDAM (Perusahaan daerah Air Minum) di Jakarta ?.

2. Bagaimana produktivitas karyawan pada PDAM (Perusahaan daerah Air Minum) di Jakarta?.

3. Adakah pengaruh antara budaya kerja terhadap produktivitas karyawan pada PDAM (Perusahaan daerah Air Minum) di Jakarta?.

\section{Tujuan Penelitian}

1. Untuk mengetahui kondisi budaya kerja pada PDAM (Perusahaan daerah Air Minum) di Jakarta.

2. Untuk mengetahui kondisi produktivitas karyawan pada PDAM (Perusahaan daerah Air Minum) di Jakarta.

3. Untuk mengetahui pengaruh antara budaya kerja terhadap produktivitas karyawan pada PDAM (Perusahaan daerah Air Minum) di Jakarta.

\section{TINJAUAN PUSTAKA}

\section{Budaya Kerja}

Budaya kerja menurut Robins (dikutip dalam Wibowo. 2010), adalah sebuah persepsi yang dipegang oleh para anggota organisasi, suatu sistem tentang keberanian bersama. Menurut Greenberg dan Baron (dikutip dalam Wibowo. 2010), menyatakan bahwa budaya kerja sebagai kerangka kerja kognitif yang terdiri dari sikap, nilai-nilai, norma perilaku dan harapan yang diterima bersama oleh anggota organisasi. Menurut Triguno (dikutip dalam Wibowo. 2010), budaya kerja merupakan suatu falsafah dengan didasari pandangan hidup sebagai nilai-nilai yang menjadi sifat, kebiasaan dan juga pendorong yang dibudayakan dalam suatu kelompok dan tercermin dalam sikap menjadi perilaku, cita-cita, pendapat, pandangan serta tindakan yang terwujud sebagai kerja. 


\section{Produktivitas Karyawan}

Produktivitas kerja adalah perbandingan kegiatan antara efektivitas keluaran dengan efektivitas masukan, artinya sebagai sikap mental yang diperlukan untuk melakukan perbaikan dan peningkatan dalam setiap pekerjaannya. (Muchdarsyah, 2010:102).

Pada dasarnya produktivitas mencakup sikap mental patriotik yang memandang hari depan secara optimis dengan berakar pada keyakinan diri bahwa kehidupan hari ini adalah lebih baik dari hari kemarin dan hari esok adalah lebih baik dari hari ini. (Sinungan, 2008:2). Produktivitas adalah perbandingan antara output (hasil) dengan input (masukan). Jika produktivitas naik ini hanya dimungkinkan oleh adanya peningkatan efisiensi waktu-bahan-tenaga) dan sistem kerja, teknik produksi dan adanya peningkatan keterampilan dari tenaga kerja. (Malayu, 2008:126).

\section{METODE PENELITIAN}

\section{Populasi}

Populasi dalam penelitian ini berjumlah 93 responden PDAM (Perusahaan daerah Air Minum) di Jakarta

\section{Sampel}

Teknik pengambilan sampling dalam penelitian ini adalah sampel jenuh, dimana semua anggota populasi dijadikan sebagai sampel. Dengan demikian sampel dalam penelitian ini sampel yang digunakan berjumlah 93 responden.

\section{Jenis Penelitian}

Jenis penelitian yang dipakai adalah asosiatif, dimana tujuannya adalah untuk mengetahui atau mencari keterhubungan antara variabel independen terhadap variabel dependennya

\section{Metode Analisis Data}

Dalam menganalisis data digunakan uji validitas, uji reliabilitas, analisis regresi linier sederhana, analisis koefisien korelasi, analisis koefisien determinasi dan pengujian hipotesis.

\section{HASIL PENELITIAN}

\section{Analisis Deskriptif}

Pada pengujian ini digunakan untuk mengetahui skor minimum dan maksimum skor tertinggi, ratting score dan standar deviasi dari masing-masing variabel. Adapun hasilnya sebagai berikut:

Tabel 1. Hasil Analisis Descriptive Statistics

Descriptive Statistics

\begin{tabular}{lr|r|r|r|r} 
& N & \multicolumn{1}{c}{ Minimum } & Maximum & Mean & Std. Deviation \\
\hline Budaya kerja (X) & 93 & 28 & 44 & 34.27 & 3.901 \\
\hline Produktivitas Karyawan (Y) & 93 & 29 & 49 & 38.55 & 4.315 \\
\hline Valid N (listwise) & 93 & & & & \\
\hline
\end{tabular}

Budaya kerja diperoleh varians minimum sebesar 28 dan varians maximum 44 dengan ratting score sebesar 3,427 dengan standar deviasi 3,901. Skor ini termasuk pada rentang sakala 3,40-4,19 dengan kriteria baik atau setuju.

Produktivitas karyawan diperoleh varians minimum sebesar 29 dan varians maximum 49 dengan ratting score sebesar 3,855 dengan standar deviasi 4,315. Skor ini termasuk pada rentang sakala 3,40 - 4,19 dengan kriteria baik atau setuju.

\section{Analisis Verifikatif}

Pada analisis ini dimaksudkan untuk mengetahui pengaruh variabel independen 
terhadap variabel dependen. Adapun hasil pengujian sebagai berikut:

\section{a. Analisis Regresi Linier Sederhana}

Uji regresi ini dimaksudkan untuk mengetahui perubahan variabel dependen jika variabel independen mengalami perubahan. Adapun hasil pengujiannya sebagai berikut:

\begin{tabular}{|c|c|c|c|c|c|}
\hline \multirow[b]{3}{*}{ Model } & \multicolumn{2}{|c|}{ Coefficients } & \multirow[b]{2}{*}{$\begin{array}{l}\text { Standardized } \\
\text { Coefficients }\end{array}$} & \multirow[b]{3}{*}{$\mathrm{t}$} & \multirow[b]{3}{*}{ Sig. } \\
\hline & \multicolumn{2}{|c|}{$\begin{array}{l}\text { Unstandardized } \\
\text { Coefficients }\end{array}$} & & & \\
\hline & $\mathrm{B}$ & Std. Error & Beta & & \\
\hline 1 (Constant) & 9.174 & 2.527 & & 3.630 & .000 \\
\hline Budaya kerja (X) & .857 & .073 & .775 & 11.698 & .000 \\
\hline
\end{tabular}

Berdasarkan hasil pengujian pada tabel di atas, diperoleh persamaan regresi $\mathrm{Y}$ $=9,174+0,857 \mathrm{X}$. Dari persamaan tersebut dijelaskan sebagai berikut:

1) Konstanta sebesar 9,174 diartikan jika budaya kerja tidak ada, maka telah terdapat nilai produktivitas karyawan sebesar 9,174 point.

2) Koefisien regresi budaya kerja sebesar 0,857 , angka ini positif artinya setiap ada peningkatan budaya kerja sebesar 0,857 point maka produktivitas karyawan juga akan mengalami peningkatan sebesar 0,857 point.

\section{b. Analisis Koefisien Korelasi}

Analisis koefisien korelasi dimaksudkan untuk mengetahui tingkat kekuatan hubungan dari variabel independen terhadap variabel dependen. Adapun hasil pengujian sebagai berikut:

Tabel 3. Hasil Pengujian Koefisien Korelasi Budaya kerja Terhadap Produktivitas

\begin{tabular}{|c|c|c|c|}
\hline & \multirow[t]{2}{*}{$\begin{array}{l}\text { Karyawan. } \\
\text { Correlations }^{\mathbf{b}}\end{array}$} & \multirow[b]{2}{*}{$\begin{array}{c}\text { Budaya kerja } \\
\text { (X1) }\end{array}$} & \\
\hline & & & $\begin{array}{l}\text { Produktivitas } \\
\text { Karyawan (Y) }\end{array}$ \\
\hline \multirow[t]{2}{*}{ Budaya kerja $(\mathrm{X})$} & Pearson Correlation & 1 & $.775^{* *}$ \\
\hline & Sig. (2-tailed) & & .000 \\
\hline \multirow[t]{2}{*}{ Produktivitas Karyawan (Y) } & Pearson Correlation & $.775^{* *}$ & 1 \\
\hline & Sig. (2-tailed) & .000 & \\
\hline
\end{tabular}

Berdasarkan hasil pengujian diperoleh nilai korelasi sebesar 0,775 artinya budaya kerja memiliki hubungan yang kuat terhadap produktivitas karyawan.

\section{c. Analisis Koefisien Determinasi}

Analisis koefisien determinasi dimaksudkan untuk mengetahui besarnya persentase pengaruh dari variabel independen terhadap variabel dependen. Adapun hasil pengujian sebagai berikut:

Tabel 4. Hasil Pengujian Koefisien Determinasi Budaya kerja Terhadap Produktivitas Karyawan.

Model Summary

\begin{tabular}{|c|c|c|c|c|}
\hline \multicolumn{5}{|c|}{ 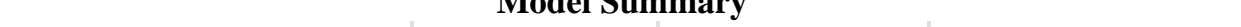 } \\
\hline Model & $\mathrm{R}$ & R Square & $\begin{array}{l}\text { Adjusted R } \\
\text { Square }\end{array}$ & $\begin{array}{l}\text { Std. Error of the } \\
\text { Estimate }\end{array}$ \\
\hline 1 & $.775^{\mathrm{a}}$ & .601 & .596 & 2.742 \\
\hline
\end{tabular}

Berdasarkan hasil pengujian diperoleh nilai determinasi sebesar 0,601 artinya budaya kerja memiliki kontribusi pengaruh sebesar $60,1 \%$ terhadap produktivitas karyawan, sedangkan sisanya sebesar 39,1\% dipengaruhi oleh faktor lain yang tidak dilakukan penelitian. 


\section{d. Uji Hipotesis}

Pengujian hipotesis dengan uji t digunakan untuk mengetahui hipotesis mana yang diterima.

Rumusan hipotesis: Terdapat pengaruh yang signifikan antara budaya kerja terhadap produktivitas karyawan.

Tabel 5. Hasil Uji Hipotesis Budaya kerja Terhadap Produktivitas Karyawan.

\begin{tabular}{|c|c|c|c|c|c|}
\hline \multirow[b]{3}{*}{ Model } & \multicolumn{2}{|c|}{ Coefficients $^{\mathrm{a}}$} & \multirow[b]{2}{*}{$\begin{array}{l}\text { Standardized } \\
\text { Coefficients }\end{array}$} & \multirow[b]{3}{*}{$\mathrm{t}$} & \multirow[b]{3}{*}{ Sig. } \\
\hline & $\begin{array}{r}\text { Unst } \\
\mathrm{Co}\end{array}$ & $\begin{array}{l}\text { dardized } \\
\text { ficients }\end{array}$ & & & \\
\hline & B & Std. Error & Beta & & \\
\hline 1 (Constant) & 9.174 & 2.527 & & 3.630 & .000 \\
\hline Budaya kerja (X) & .857 & .073 & 775 & 11698 & .000 \\
\hline
\end{tabular}

Berdasarkan hasil pengujian pada tabel di atas, diperoleh nilai t hitung $>\mathrm{t}$ tabel atau $(11,698>1,986)$, dengan demikian hipotesis yang diajukan bahwa terdapat pengaruh yang signifikan atara budaya kerja terhadap produktivitas karyawan diterima.

\section{Pembahasan Hasil Penelitian}

\section{Kondisi Jawaban Responden Variabel Budaya kerja}

Berdasarkan jawaban responden, variabel budaya kerja diperoleh ratting score sebesar 3,427 berada di rentang skala 3,40-4,19 dengan kriteria baik atau setuju.

\section{Kondisi Jawaban Responden Variabel Produktivitas Karyawan}

Berdasarkan jawaban responden, variabel produktivitas karyawan diperoleh ratting score sebesar 3,855 berada di rentang skala 3,40-4,19 dengan kriteria baik atau setuju.

\section{Pengaruh Budaya kerja Terhadap Produktivitas Karyawan}

Budaya kerja berpengaruh signifikan terhadap produktivitas karyawan dengan persamaan regresi $\mathrm{Y}=9,174+0,857 \mathrm{X}$, nilai korelasi sebesar 0,775 atau memiliki hubungan yang kuat dengan kontribusi pengaruh sebesar 60,1\%. Pengujian hipotesis diperoleh nilai t hitung $>\mathrm{t}$ tabel atau $(11,698>1,986)$. Dengan demikian hipotesis yang diajukan bahwa terdapat berpengaruh signifikan antara budaya kerja terhadap produktivitas karyawan diterima.

\section{KESIMPULAN DAN SARAN}

\section{Kesimpulan}

a. Variabel budaya kerja diperoleh ratting score sebesar 3,427 berada di rentang skala 3,40 - 4,19 dengan kriteria baik atau setuju.

b. Variabel produktivitas karyawan diperoleh ratting score sebesar 3,855 berada di rentang skala 3,40 - 4,19 dengan kriteria baik atau setuju.

c. Budaya kerja berpengaruh signifikan terhadap produktivitas karyawan dengan persamaan regresi $\mathrm{Y}=9,174+0,857 \mathrm{X}$, nilai korelasi sebesar 0,775 atau kuat dan kontribusi pengaruh sebesar $60,1 \%$ sedangkan sisanya sebesar $39,1 \%$ dipengaruhi faktor lain. Uji hipotesis diperoleh nilai thitung > t tabel atau $(11,698>1,986)$.

\section{Saran}

a. Diharapkan agar karyawan/ti dapat menerapkan semua budaya kerja yang telah ditetapkan oleh perusahaan agar tujuan dari perusahaan dapat terlaksanakan. Terutama dalam hal pulang tepat waktu dan tidak sering izin, karena masih adanya 
karyawan/ti tidak setuju dengan ndikator budaya ini.

b. Diharapkan agar karyawan dapat meningkatkan produktivitas kerjanya, karena masih adanya karyawan/ti dengan hasil kerja yang tidak sesuai dengan harapan perusahaan, yaitu dengan cara menerapkan budaya kerja yang telah ditetapkan oleh perusahaan.

c. Diharapkan dapat dilakukan penelitian lanjutan untuk mengetahui 65actor-faktor apa saja yang memperngaruhi produktivitas kerja, sehingga dapat diketahui cara yang bagaimana untuk meningkatkan produktivitas kerja.

\section{DAFTAR PUSTAKA}

AM, E. N., Sarwani, S., Akbar, I. R., Mas' adi, M., \& Maddinsyah, A. (2021). Pengaruh Kedisiplinan Dan Pemberian Kesejahteraan Terhadap Kinerja Pegawai Pada Unit Pelaksana Teknis Puskesmas Wilayah Tangerang Selatan. JENIUS (Jurnal Ilmiah Manajemen Sumber Daya Manusia), 4(2), 185-200.

Gomes, Faustino. 2003. Manajemen Sumber Daya Manusia. Yogyakarta: Andi

Hasibuan Malayu. 2008. Organisasi Dan Motivasi Dasar Peningkatan Produktivitas. Jakarta: PT. Bumi Aksara.

Ivancevich M. John, Konopaske Robert, dan Matteson T. Michael. 2006. Perilaku dan Manajemen Organisasi. Jakarta: PT. Gelora Aksara Pratama.

Kerja Pegawai Dinas Perhubungan Kota Bekasi. Skripsi: Universitas Gunadarma.

Koesmono H. Teman. 2005. "Pengaruh Budaya Organisasi Terhadap Motivasi Dan

Kepuasan Kerja Serta Kinerja Karyawan Pada Sub Sektor Industri Pengolahan Kayu Skala Menengah Di Jawa Timur”. Jurnal manajemen \& kewirausahaan, Vol. 7 No. 2, September 2005: 171-188.

Kreitner R and Angele Kinichi. 2003. Organizational Behavior. Terjemahan Erdy Swandy. Jakarta : Salemba Empat.

Kristianti, LS. D Sunarsi. (2020). Pengaruh Motivasi Dan Pengalaman Kerja Terhadap Produktivitas Karyawan Pada PT. Mobilindo Perkasa Di Tangerang. Value: Jurnal Manajemen dan Akuntansi 15 (2), 87-95.

Kustini, E., et al. (2021). Pengaruh Keterampilan Kerja Dan Lingkungan Kerja Terhadap Kinerja Karyawan Pada PT. Garuda Daya Pratama Sejahtera (Garuda Indonesia Group). Jurnal Ilmiah PERKUSI, 1(3), 305-314.

Mathis L. Robert and Jhon H. Jackson. 2006. Human Resource Management. Jakarta: Salemba Empat.

Matindas, R. 2002. Manajemen S.D.M. Jakarta: Pustaka Utama Grafiti.

Moleong J. Lexy. 2009. Metodologi Penelitian Kuantitatif. Bandung: PT. Remaja Rosdakarya.

Mulyadi. 2007. Manajemen Sumber Daya Manusia. Jakarta: Gramedia.

Nowipa, Reza. 2009. Pengaruh Motivasi dan Budaya Organisasi Terhadap Produktivitas

Nurjaya, N., et al. (2021). Pengaruh Kompetensi Sumber Daya Manusia Dan Kemampuan Pemanfaatan Teknologi Terhadap Kinerja Aparatur Desa Pada Kantor Kepala Desa Di Kabupaten Gunungkidul, Yogyakarta. JENIUS (Jurnal Ilmiah Manajemen Sumber Daya Manusia), 4(3), 332-346.

Nurjaya, N., Sunarsi, D., Effendy, A. A., Teriyan, A., \& Gunartin, G. (2021). Pengaruh Etos Kerja Dan Disiplin Kerja Terhadap Kinerja Pegawai Pada Dinas Kehutanan Dan Perkebunan Kota Bogor. JENIUS (Jurnal Ilmiah Manajemen Sumber Daya Manusia), 4(2), 172-184.

Pitriana, Eleonora. 2008. Pengaruh Budaya Perusahaan Terhadap Kinerja Karyawan Divisi SDM \& Umum Pada PT. Pertamina (Persero) Unit Pemasaran II (Upms II) 
Palembang. Skripsi : Universitas Sriwijaya.

Prasada, D., Sunarsi, D., \& Teriyan, A. (2020). Pengaruh Etos Kerja Dan Kompensasi Terhadap Komitmen Organisasi Pada DHL Logistic Di Jakarta. JENIUS (Jurnal Ilmiah Manajemen Sumber Daya Manusia), 4(1), 51-60.

Rizal, Hanif. 2012. Pengaruh Budaya Organisasi dan Kepuasan Kerja terhadap Kinerja Karyawan. Skripsi : Universitas Diponegoro.

Robbins S. Ptephen. 2001. Organization Behaviour, Alih Bahasa Hadyana. Jakarta : Prenhaltindo.

Salim, A. O., et al. (2020). Pengaruh Jaminan Sosial Tenaga Kerja Terhadap Produktivitas Kerja Karyawan Pada PT Sumber Abadi Indonesia Cabang Kota Sorong Papua Barat. Jurnal Ilmiah Manajemen Emor (Ekonomi Manajemen Orientasi Riset), 4(1), 32-40.

Sedarmayanti. 2010. Manajemen Sumber Daya Manusia. Bandung: PT. Refika Aditama.

Sinungan Muchdarsyah. 2008. Produktivitas Apa dan Bagaimana. Jakarta: Bumi Aksara.

Sugiyono. 2004. Statistika Untuk Penelitian. Jakarta: Alfabeta.

Suwanto, S., et al. (2021). Pengaruh Motivasi Dan Pengalaman Kerja Terhadap Produktivitas Karyawan Pada Happy Restaurant Di Bandung. Jurnal Ekonomi Efektif, 3(4), 546-554.

Tika, Pabundu. 2006. Budaya Organisasi dan Peningkatan Budaya Organisasi. Jakarta Bumi Aksara.

Wibowo. 2006. Manajemen Perubahan. Jakarta : Raja Grafindo Persada.

Wibowo. 2010. Budaya Organisasi : Sebuah Kebutuhan Meningkatkan Kinerja Jangka Panjang. Jakarta : Rajawali Pers.

Yanna. 2011. Pengaruh Budaya Kerja Terhadap Prestasi Kerja Karyawan di JM Pasaraya (Letkol Iskandar) Palembang. Skripsi : Unversitas Sriwijaya. 